\title{
A Fuzzy-MOORA approach for ERP system selection
}

\author{
Prasad Karande $^{\mathrm{a}}$ and Shankar Chakraborty ${ }^{\mathrm{b} *}$
}

${ }^{a}$ Mechanical Engineering Department, Government Polytechnic, Mumbai - 400 051, Maharashtra, India

${ }^{b}$ Department of Production Engineering, Jadavpur University, Kolkata - 700032, India

\begin{tabular}{l}
\hline A R T I C L E I N F O \\
\hline Article history: \\
Received June 9, 2012 \\
Accepted 5 July 2012 \\
Available online \\
July 62012 \\
\hline Keywords: \\
ERP system \\
MOORA method \\
Fuzzy theory \\
Triangular membership function
\end{tabular}

\section{A B S T R A C T}

\begin{abstract}
In today's global and dynamic business environment, manufacturing organizations face the tremendous challenge of expanding markets and meeting the customer expectations. It compels them to lower total cost in the entire supply chain, shorten throughput time, reduce inventory, expand product choice, provide more reliable delivery dates and better customer service, improve quality, and efficiently coordinate demand, supply and production. In order to accomplish these objectives, the manufacturing organizations are turning to enterprise resource planning (ERP) system, which is an enterprise-wide information system to interlace all the necessary business functions, such as product planning, purchasing, inventory control, sales, financial and human resources into a single system having a shared database. Thus to survive in the global competitive environment, implementation of a suitable ERP system is mandatory. However, selecting a wrong ERP system may adversely affect the manufacturing organization's overall performance. Due to limitations in available resources, complexity of ERP systems and diversity of alternatives, it is often difficult for a manufacturing organization to select and install the most suitable ERP system. In this paper, two ERP system selection problems are solved using fuzzy multi-objective optimization on the basis of ratio analysis (MOORA) method and it is observed that in both the cases, SAP is the best solution.
\end{abstract}

\section{Introduction}

Enterprise resource planning (ERP) is a comprehensive integrated information system comprising several configurable modules to automate the flow of material, information and financial resources among all the functions within a manufacturing organization on a common database. Besides integration, its main aim is to enhance decision support, reduce asset costs, receive more accurate and timely information, and attain higher flexibility with increased customer satisfaction. To survive in the global competitive environment, every organization now feels the need to augment a suitable ERP system in its present operational structure. Although implementing an ERP system is cost-extensive and time-consuming task, its benefits are worthwhile. With careful selection of an ERP system, a

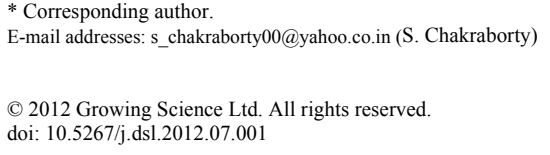


manufacturing organization can expect to achieve significant advantages, including dramatic increase in responsiveness, productivity, on-time shipment and sales, as well as decreases in lead time, purchase cost, quality problem and inventory. Failure in selecting an appropriate ERP system may lead to failure of the project or the organization's performance will get weakened.

Nowadays, most of the manufacturing organizations do not only implement ERP systems themselves, but also expect to have the full support of ERP software developers after installation, because ERP software is an expensive tool and requires well-defined contributions between the manufacturing organization and a developer or its vendor/consultant firm. On the other hand, an ERP software in market cannot fully meet the needs and expectations of organizations, because every organization runs its own business with different strategies and goals. ERP vendors/developers use different hardware platforms, databases and operation systems, and some ERP software is only compatible with some organizations' databases and operation systems. However, many manufacturing organizations install their ERP systems hurriedly without fully understanding the implications for their business or the need for compatibility with overall organizational goals and strategies. Surprisingly, given the significant investment in resources and time, many organizations did not achieve success in ERP implementation. It is estimated that the failure rate of ERP implementation ranges from $40 \%$ to $60 \%$ or higher (Nazemi et al., 2012).

Therefore, the selection process for finding out the most satisfying ERP software among a set of feasible alternatives in market should be achieved using one of the proven multi-criteria decisionmaking (MCDM) methods. By following an MCDM-based methodology, the decision maker should be able to strengthen the selection decision with respect to justifiability, accountability and reasonability, which are regularly seen as pre-requisites of complex and risky decisions. In this paper, the application of fuzzy multi-objective optimization on the basis of ratio analysis (MOORA) method is proposed to choose the best ERP systems for two manufacturing organizations. It is also proved that fuzzy MOORA method is a simple, easy to understand and accurate tool for solving decisionmaking problems having imprecise and vague evaluation data.

\section{Literature review}

Shyur (2003) developed an analytic network process (ANP)-based four-step semi-structured method for ERP system evaluation having interdependency relations among the considered multiple criteria. Wei and Wang (2004) presented a comprehensive framework for combining objective data obtained from external professional reports and subjective data accumulated from internal interviews with vendors to select a suitable ERP project. Bernroider and Mitlöhner (2005) observed an increase in awareness of MCDM methods in the context of ERP project selection and concluded that although the ERP selection decision problem would seem to be structured, formal MCDM methods would be quite helpful to solve that decision-making problem. Wei et al. (2005) presented a comprehensive method for selecting a suitable ERP system based on a framework which could construct the objectives of ERP selection to support the business goals and strategies of an organization, identify the appropriate attributes and set up a consistent evaluation standard for facilitating a group decision process. Lien and Liang (2005) proposed a three-phase ERP selection framework using fuzzy analytic hierarchy process (FAHP) and observed that cost was the most important factor affecting the ERP system selection decision. Liao et al. (2007) proposed a similarity degree-based algorithm to aggregate the objective information about ERP systems from some external professional organizations, which might be expressed by different linguistic terms. The consistency and inconsistency indices were defined by considering the subjective information obtained from internal interviews with the ERP vendors, and a linear programming model was established for selecting the most suitable ERP system. Ayağ and Özdemir (2007) applied a fuzzy extension of ANP method for selecting a suitable ERP system while considering various interactions, dependencies and feedback between higher- and lower-level elements in the decision-making process. Liang and Lien (2007) presented a practical procedure while combining both the ISO 9126 standard and FAHP approach to optimize the ERP selection problems. Lien and Chan (2007) proposed a FAHP method to develop a 
selection model for ERP system. Karaarslan and Gundogar (2008) aimed to select the most appropriate ERP software from two elected candidates using AHP method. Karsak and Özogul (2009) proposed an integrated decision framework for ERP software selection based on quality function deployment, fuzzy linear regression and zero-one goal programming methods. It was observed that the developed methodology would appear as a sound investment decision-making tool for ERP systems as well as other information systems. Yazgan et al. (2009) designed an artificial neural network-based model and trained with ANP in order to calculate priority values to select the best ERP software. Cebeci (2009) presented an approach to select a suitable ERP system for a textile industry and used FAHP method to compare the performance of ERP system solutions. Onut and Efendigil (2010) applied AHP method and its fuzzy extension to obtain more decisive judgments by prioritizing criteria and assigning weights to the ERP system alternatives. Forslund and Jonsson (2010) studied the effects of decisions made in the ERP system lifecycle phases on supply chain performance management. Asgari et al. (2011) introduced a comprehensive framework for selecting ERP system using fuzzy theory and fuzzy MCDM methods. Nikjoo et al. (2011) employed decision techniques and combined with goal programming to choose an appropriate ERP system for a particular manufacturing organization. Rouyendegh and Erkan (2011) presented a comprehensive framework for selecting the best suited ERP system using AHP method. It could systematically construct the objectives of an ERP system selection to support the business goals and strategies of the organization. Khaled and Idrissi (2011) addressed the question of how to choose an ERP solution that would best suit a given small and medium enterprise. Choquet integral was introduced as a new iterative learning-based approach destined to make enlightened decisions through the consideration of interdependencies among the adopted selection criteria. Huiqun and Guang (2012) developed a novel approach while integrating AHP and rough set theory for ERP software selection, and applied fuzzy technique for order preference by similarity to ideal solution (FTOPSIS) method to obtain final ranking of the ERP software alternatives. Although the earlier researchers have focused their attention on selecting the most suitable ERP systems using complex mathematical tools, a need is still felt to apply a simple and easily understandable MCDM method to deal with the ERP system selection problems.

\section{Fuzzy MOORA method}

The method of multi-objective optimization on the basis of ratio analysis (MOORA) was introduced by Brauers and Zavadskas (2006). Due to its simplicity and comprehensiveness, it has already been successfully applied in manufacturing (Chakraborty, 2010), construction engineering and management (Kracka et al., 2010; Brauers et al., 2008; Brauers et al., 2008), and economics (Brauers \&Ginevicious, 2009; Brauers \& Zavadskas, 2010). MOORA is the process of simultaneously optimizing two or more conflicting attributes (objectives) subject to certain constraints. In a decisionmaking problem, the values of these objectives are measured for every decision alternative, and this provides the basis of comparison of choices and consequently facilitates the selection of the best (satisfactory) option. Therefore, multi-objective optimization techniques seem to be an appropriate tool for ranking or selecting one or more alternatives from a set of feasible options based on multiple, usually conflicting attributes. It has been already observed that MOORA method is very simple, stable and robust, and it requires minimum mathematical calculations and computational time (Chakraborty, 2010; Brauers \& Zavadskas, 2012).

In MOORA method, the overall performance of each alternative is calculated as the difference between sums of its normalized performances for beneficial and non-beneficial criteria, using the following expression:

$y_{i}=\sum_{j=1}^{g} x_{i j}^{*}-\sum_{j=g+1}^{n} x_{i j}^{*}$ 
where $x_{i j}{ }^{*}$ is a dimensionless number in the interval of [0,1] representing the normalized performance of $i^{\text {th }}$ alternative on $j^{\text {th }}$ criterion, $g$ is the number of beneficial criteria, $(n-g)$ is the number of nonbeneficial criteria and $y_{i}$ is the overall performance of $i^{\text {th }}$ alternative with respect to all the criteria.

When priority weights are considered to give relative importance of one criterion over the other, Eq. (1) can be rewritten as:

$$
y_{i}=\sum_{j=1}^{g} w_{j} x_{i j}^{*}-\sum_{j=g+1}^{n} w_{j} x_{i j}^{*} \quad(j=1,2, \ldots, n)
$$

where $w_{j}$ is the weight of $j^{\text {th }}$ criterion which can be determined by AHP or entropy method. The best alternative has the highest $y_{i}$ value, while the lowest $y_{i}$ value represents the worst alternative.

Fuzzy set theory provides a mathematical framework in which vague conceptual phenomena can be precisely studied (Zadeh, 1965). It has already been proven to be a valuable tool to strengthen the comprehensiveness and reasonableness of the decision-making process. It is an important method to measure the ambiguity of concepts that are associated with the decision maker's subjective judgments, including linguistic terms, satisfaction degree and importance degree that are often vague. A fuzzy set $\bar{A}$ in a universe of discourse $X$ is characterized by a membership function $\mu_{\bar{A}}(x)$ which associates with each element $x$ in $X$ a real number in the interval $[0,1]$. The function value $\mu_{\bar{A}}(x)$ is termed as the grade of membership of $x$ in $\bar{A}$. The most commonly used fuzzy numbers are triangular and trapezoidal fuzzy numbers. Triangular fuzzy numbers are often used in applications because of their calculation easiness and added features. The triangular fuzzy numbers can be denoted as $\bar{A}=(l$, $m, n)$ and the membership function of fuzzy number $\bar{A}$ is defined by the following equation.

$\mu_{\bar{A}}(x)=\left\{\begin{array}{rl}0 & x<l, \\ \frac{x-l}{m-l} & l \leq x \leq m, \\ \frac{n-x}{n-m} & m \leq x \leq n, \\ 0 & x>n\end{array}\right.$

Fig. 1 exhibits a triangular fuzzy membership function. In this membership function, the triangles are completed with the minimum and maximum points attached to the adjacent center. It is spaced equally according to the minimum and maximum values of the input data.

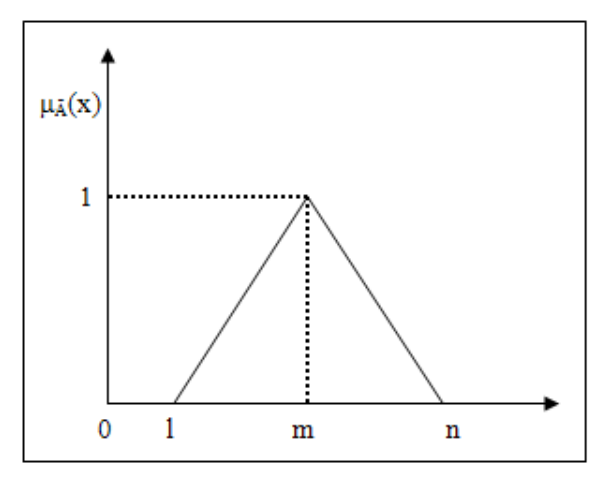

Fig. 1. A triangular fuzzy membership function

In order to take full advantage of MOORA method for solving the decision-making problems with imprecise and vague data, a new variant of MOORA method, i.e. fuzzy MOORA is proposed here which consists of the following procedural steps. 
Step 1: Based on the valued opinions of the decision makers, develop the fuzzy decision matrix where each criterion value is measured using triangular membership function.

$$
X=\left[\begin{array}{cccc}
{\left[x_{11}^{l}, x_{11}^{m}, x_{11}^{n}\right]} & {\left[x_{12}^{l}, x_{12}^{m}, x_{12}^{n}\right]} & \ldots & {\left[x_{1 n}^{l}, x_{1 n}^{m}, x_{1 n}^{n}\right]} \\
{\left[x_{21}^{l}, x_{21}^{m}, x_{2 l}^{n}\right]} & {\left[x_{22}^{l}, x_{22}^{m}, x_{22}^{n}\right]} & \ldots & {\left[x_{2 n}^{l}, x_{2 n}^{m}, x_{2 n}^{n}\right]} \\
\ldots & \ldots & \ldots & \ldots \\
{\left[x_{m 1}^{l}, x_{m l}^{m}, x_{m l}^{n}\right]} & {\left[x_{m 2}^{l}, x_{m 2}^{m}, x_{m 2}^{n}\right]} & \ldots & {\left[x_{m n}^{l}, x_{m n}^{m}, x_{m n}^{n}\right]}
\end{array}\right]
$$

where $x_{i j}{ }^{l}, x_{i j}{ }^{m}$ and $x_{i j}{ }^{n}$ respectively denote the lower, middle and upper values of a triangular membership function for $i^{\text {th }}$ alternative with respect to $j^{\text {th }}$ criterion.

Step 2: Normalize the fuzzy decision matrix using vector normalization procedure. For this, the following equations are adopted (Stanujkic et al., 2012).

$$
\begin{aligned}
& r_{i j}^{l}=\frac{x_{i j}^{l}}{\sqrt{\sum_{i=1}^{m}\left[\left(x_{i j}^{l}\right)^{2}+\left(x_{i j}^{m}\right)^{2}+\left(x_{i j}^{n}\right)^{2}\right]}} \\
& r_{i j}^{m}=\frac{x_{i j}^{m}}{\sqrt{\sum_{i=1}^{m}\left[\left(x_{i j}^{l}\right)^{2}+\left(x_{i j}^{m}\right)^{2}+\left(x_{i j}^{n}\right)^{2}\right]}} \\
& r_{i j}^{n}=\frac{x_{i j}^{n}}{\sqrt{\sum_{i=1}^{m}\left[\left(x_{i j}^{l}\right)^{2}+\left(x_{i j}^{m}\right)^{2}+\left(x_{i j}^{n}\right)^{2}\right]}}
\end{aligned}
$$

Step 3: Determine the weighted normalized fuzzy decision matrix employing the following equations:

$$
\begin{aligned}
& v_{i j}^{l}=w_{j} r_{i j}^{l} \\
& v_{i j}^{m}=w_{j} r_{i j}^{m} \\
& v_{i j}^{n}=w_{j} r_{i j}^{n}
\end{aligned}
$$

For the development of the weighted normalized fuzzy decision matrix, fuzzy criteria weights may also be used, but this leads to more complex calculations.

Step 4: Calculate the overall ratings of beneficial and non-beneficial criteria for each alternative. For beneficial criteria, the overall ratings of an alternative for lower, middle and upper values of the triangular membership function are computed as follows:

$$
\begin{aligned}
& S_{i}^{+l}=\sum_{j=1}^{n} v_{i j}^{l} \mid j \in J^{\max } \\
& S_{i}^{+m}=\sum_{j=1}^{n} v_{i j}^{m} \mid j \in J^{\max }
\end{aligned}
$$


$S_{i}^{+n}=\sum_{j=1}^{n} v_{i j}^{n} \mid j \in J^{\max }$

On the other hand, for non-beneficial criteria, the overall ratings of an alternative are calculated as follows,

$$
\begin{aligned}
& s_{i}^{-l}=\sum_{j=1}^{n} v_{i j}^{l} \mid j \in J^{m i n} \\
& s_{i}^{-m}=\sum_{j=1}^{n} v_{i j}^{m} \mid j \in J^{m i n} \\
& s_{i}^{-n}=\sum_{j=1}^{n} v_{i j}^{n} \mid j \in J^{\min }
\end{aligned}
$$

Step 5: Determine the overall performance index $\left(S_{i}\right)$ for each alternative. For this, the defuzzied values of the overall ratings for beneficial and non-beneficial criteria for each alternative are computed using the vertex method (Huiqun \& Guang, 2012), as follows,

$$
S_{i}\left(s_{i}^{+}, s_{i}^{-}\right)=\sqrt{\frac{1}{3}\left[\left(s_{i}^{+l}-s_{i}^{-l}\right)^{2}+\left(s_{i}^{+m}-s_{i}^{-m}\right)^{2}+\left(s_{i}^{+n}-s_{i}^{-n}\right)^{2}\right]}
$$

Step 6: Based on the descending values of overall performance index, rank the alternatives from the best to the worst. The alternative with the highest overall performance index is the most favorable choice.

\section{Illustrative examples}

While selecting the best ERP system solution for a specific manufacturing organization, the decision maker has to take into account various critical factors influencing its successful deployment. Those important factors are enlisted in details here-in-under.

a) Corporate vision

i) What major organizational changes has the ERP vendor/developer made recently?

ii) What major product changes does the organization foresee or has planned in near future?

iii) What level of involvement does the executive staffs have in the organization's daily operations?

b) Technology and system architecture

i) Is the technology robust enough to handle current and future transactions?

ii) Is the system's speed acceptable for daily use?

iii) Is source code provided so that customizations or modifications can be easily made?

iv) Does the ERP system allow a number of database and server options?

v) Does the ERP system support multi-organization, multi-division and multi-locational environments?

c) Product functionality

i) Does this ERP system meet the overall requirements? 
ii) Is the menu structure easy to follow and understand?

iii) Are the help files easily assessable and easy for users to comprehend?

iv) Can the user customize help files to meet the organizational needs?

v) Is the product complicated or too sophisticated for the average user?

vi) Are there useful standard reports available?

d) Product cost

i) Are the license costs justified given the offered functionalities?

ii) Is the required database affordable?

iii) Are annual maintenance charges reasonable?

iv) What is the true implementation service-to-software ratio for the organization?

v) How quickly can payback be received?

e) Service and support

i) Is the team comfortable with the sales process and representative?

ii) Can the ERP vendor provide a complete turn-key solution?

iii) What type of project management is available?

iv) What type of training is available?

v) What is the average technical support staff's experience level and tenure in the organization?

vi) How quick can the non-critical software bugs be fixed?

vii) Does the ERP vendor offer business process re-engineering as part of the implementation process?

viii) Does the ERP system vendor have experience in other industries?

f) Vendor longevity

i) How many years has the organization been actively engaged in this software industry?

ii) When was the product's first release?

iii) Has the organization been consistently profitable over the years?

iv) Has there been recent turnover in the management staff?

v) Are the customer references available?

\subsection{Example 1}

In this example, Huiqun and Guang (2012) considered four ERP system selection firms, i.e. CAMANMAN/X, BAAN, SSA-BPCS and SAP R/3, and observed that apart from cost, low risk, high quality, flawless product, high reliability and delivery-on-time would be the key indicators for evaluating the performance of an ERP system selection firm. Five important criteria for software selection were identified as risk (R), quality (Q), effectiveness (E), efficiency (EF) and user satisfaction (US), and AHP method was then employed to determine the weights of those five criteria as $\mathrm{w}_{\mathrm{R}}=0.364, \mathrm{w}_{\mathrm{Q}}=0.271, \mathrm{w}_{\mathrm{E}}=0.203, \mathrm{w}_{\mathrm{EF}}=0.093$ and $\mathrm{w}_{\mathrm{US}}=0.068$. Using triangular fuzzy membership function, the fuzzy decision matrix for this ERP system selection problem was developed, as given in Table 1 and fuzzy TOPSIS method was applied to determine the best alternative as SAP R/3, whereas, SSA-BPCS was the worst chosen ERP system. 
For solving the same problem using fuzzy MOORA method, at first, the fuzzy decision matrix containing the criteria values expressed in triangular fuzzy numbers, is normalized using Eqns. (5)(7). This normalized fuzzy decision matrix is shown in Table 2. Normalization is essential for an MCDM method to make the elements of the decision matrix dimensionless and comparable. Table 3 exhibits the weighted normalized fuzzy decision matrix which is obtained after multiplying the normalized fuzzy criteria values with the corresponding values of crisp criteria weights. Among these five selection criteria, risk is the only non-beneficial attribute where lower value is preferred, and on the other hand, higher values are always desired for quality, effectiveness, efficiency and user satisfaction. Now using Eqns. (11)-(13), the overall ratings of beneficial criteria for the considered alternatives are calculated. Similarly, applying Eqns. (14)-(16), the overall ratings of non-beneficial criteria for the alternatives are computed. These overall ratings for both beneficial and non-beneficial criteria for the four alternative ERP systems are given in Table 4. Now, the vertex method is employed to defuzzify the overall ratings for beneficial and non-beneficial criteria so as to derive the values of overall performance index for all the alternatives. It is observed that the highest value of overall performance index occurs for alternative 4 , which signifies that SAP R/3 is the best ERP system to be implemented. Alternative 3 (SSA-BPCS) is the worst favored ERP system. CAMANMAN/X and BAAN are the intermediate choices. Huiqun and Guang (2012) also obtained the same rankings for these ERP systems using fuzzy TOPSIS method.

Table 1

Fuzzy ERP system selection decision matrix for example 1

\begin{tabular}{llllll}
\hline ERP system & Risk & Quality & Effectiveness & Efficiency & User satisfaction \\
\hline $\mathrm{A}_{1}$ & $(0.6,0.8,1)$ & $(0.6,0.8,1)$ & $(0.4,0.6,0.8)$ & $(0.2,0.4,0.6)$ & $(0.8,1,1)$ \\
$\mathrm{A}_{2}$ & $(0.4,0.6,0.8)$ & $(0.6,0.8,1)$ & $(0.4,0.6,0.8)$ & $(0.8,1,1)$ & $(0.2,0.4,0.6)$ \\
$\mathrm{A}_{3}$ & $(0.8,1,1)$ & $(0.4,0.6,0.8)$ & $(0.6,0.8,1)$ & $(0,0.2,0.4)$ & $(0,0.2,0.4)$ \\
$\mathrm{A}_{4}$ & $(0.2,0.4,0.6)$ & $(0.4,0.6,0.8)$ & $(0.4,0.6,0.8)$ & $(0.6,0.8,1)$ & $(0.4,0.6,0.8)$ \\
\hline
\end{tabular}

Table 2

Normalized fuzzy decision matrix for example 1

\begin{tabular}{llllll}
\hline $\begin{array}{l}\text { ERP } \\
\text { system }\end{array}$ & Risk & Quality & Effectiveness & Efficiency & User satisfaction \\
\hline $\mathrm{A}_{1}$ & $(0.238,0.317,0.396)$ & $(0.239,0.318,0.398)$ & $(0.171,0.256,0.342)$ & $(0.086,0.172,0.258)$ & $(0.375,0.468,0.468)$ \\
$\mathrm{A}_{2}$ & $(0.159,0.238,0.317)$ & $(0.239,0.318,0.398)$ & $(0.171,0.256,0.342)$ & $(0.344,0.430,0.430)$ & $(0.094,0.187,0.281)$ \\
$\mathrm{A}_{3}$ & $(0.317,0.396,0.396)$ & $(0.159,0.239,0.318)$ & $(0.256,0.342,0.427)$ & $(0,0.086,0.172)$ & $(0,0.094,0.187)$ \\
$\mathrm{A}_{4}$ & $(0.079,0.159,0.238)$ & $(0.159,0.239,0.318)$ & $(0.171,0.256,0.342)$ & $(0.258,0.344,0.430)$ & $(0.187,0.281,0.375)$ \\
\hline
\end{tabular}

Table 3

Weighted normalized fuzzy decision matrix for example 1

\begin{tabular}{llllll}
\hline $\begin{array}{l}\text { ERP } \\
\text { system }\end{array}$ & Risk & Quality & Effectiveness & Efficiency & User satisfaction \\
\hline $\mathrm{A}_{1}$ & $(0.087,0.115,0.144)$ & $(0.065,0.086,0.109)$ & $(0.035,0.052,0.069)$ & $(0.008,0.016,0.024)$ & $(0.025,0.032,0.032)$ \\
$\mathrm{A}_{2}$ & $(0.058,0.087,0.115)$ & $(0.065,0.086,0.109)$ & $(0.035,0.052,0.069)$ & $(0.032,0.040,0.040)$ & $(0.006,0.013,0.019)$ \\
$\mathrm{A}_{3}$ & $(0.115,0.144,0.144)$ & $(0.043,0.065,0.086)$ & $(0.052,0.069,0.087)$ & $(0,0.008,0.016)$ & $(0,0.006,0.013)$ \\
$\mathrm{A}_{4}$ & $(0.029,0.058,0.087)$ & $(0.043,0.065,0.086)$ & $(0.035,0.052,0.069)$ & $(0.024,0.032,0.040)$ & $(0.013,0.019,0.025)$ \\
\hline
\end{tabular}

Table 4

Ranking of ERP systems for example 1

\begin{tabular}{lllllllll}
\hline ERP system & $S^{+}$ & \multicolumn{9}{c}{$S$} & \multicolumn{2}{c}{} & \multirow{2}{*}{ Rank } \\
\cline { 2 - 7 } & $l$ & $m$ & $u$ & $l$ & $m$ & $u$ & \\
\hline $\mathrm{A}_{1}$ & 0.133 & 0.186 & 0.234 & 0.087 & 0.115 & 0.144 & 0.0713 \\
$\mathrm{~A}_{2}$ & 0.138 & 0.191 & 0.237 & 0.058 & 0.087 & 0.115 & 0.1034 & 2 \\
$\mathrm{~A}_{3}$ & 0.095 & 0.148 & 0.202 & 0.115 & 0.144 & 0.144 & 0.0355 & 4 \\
$\mathrm{~A}_{4}$ & 0.115 & 0.168 & 0.220 & 0.029 & 0.058 & 0.087 & 0.1113 & 1 \\
\hline
\end{tabular}




\subsection{Example 2}

After thoroughly investigating the effects of all the possible criteria on the final ERP system selection decision, Nikjoo et al. (2011) shortlisted five criteria, i.e. business volume (BV), rate of market share (RMS), customization (C), user interface (UI), and support services and after sale (SSS) according to their relative importance. Three alternative ERP systems, i.e. SAP, ORACLE, AXAPTA were considered, and three experts familiar with ERP systems were asked to judge and analyze about each criterion's satisfaction level by each alternative. They were also asked to determine the importance of each criterion using language variables. They explained their opinions in fuzzy numbers as expressed in trapezoid fuzzy membership functions. These trapezoid fuzzy numbers are transformed into triangular fuxxy membership functions, as given in Table 5. Then, the language variables associated with the corresponding criteria weights are changed into crisp values, and are normalized as $\mathrm{w}_{\mathrm{BV}}=$ $0.1823, \mathrm{w}_{\mathrm{RMS}}=0.2138, \mathrm{w}_{\mathrm{C}}=0.2078, \mathrm{w}_{\mathrm{UI}}=0.1842$ and $\mathrm{w}_{\mathrm{SSS}}=0.2119$. Here, maximum weights are allocated to rate of market share, and support services and after sale criteria. It is interesting to note that all these five criteria are beneficial in nature where higher values are desired. Using fuzzy TOPSIS method, Nikjoo et al. (2011) identified SAP as the best ERP system to be implemented for the considered organization.

When this ERP system selection problem is solved using fuzzy MOORA method, the fuzzy decision matrix is first normalized, as given in Table 6. After that, the weighted normalized fuzzy decision matrix is obtained and is exhibited in Table 7. As all the five criteria are beneficial in nature, the overall ratings of beneficial criteria for each alternative are only required to be calculated, as shown in Table 8. These overall ratings of beneficial criteria are now defuzzified using Eq. (17) to obtain the corresponding overall performance indices for the three ERP system alternatives. Based on these overall performance index values, the alternatives ERP systems are ranked and it is clear that SAP emerges out as the best ERP system, followed by ORACLE. Axapta obtains the last rank. It is worthwhile to mention here that Nikjoo et al. (2011) also derived the same rankings for these three ERP system alternatives. These results evidently suggest the feasibility, usefulness and accuracy of fuzzy MOORA method in solving ERP system selection problems.

\section{Table 5}

Fuzzy decision matrix for ERP system selection problem for example 2

\begin{tabular}{llllll}
\hline ERP system & BV & RMS & C & UI & SSS \\
\hline ORACLE & $(7,8.8,10)$ & $(7,8.5,10)$ & $(5,7,9)$ & $(7,8.5,10)$ & $(7,8.5,10)$ \\
SAP & $(7,9,10)$ & $(5,8.5,10)$ & $(5,7.5,9)$ & $(7,8.5,10)$ & $(7,9,10)$ \\
Axapta & $(1,5.5,9)$ & $(2,4,6)$ & $(1,4.5,8)$ & $(4,7,10)$ & $(2,4,6)$ \\
\hline
\end{tabular}

\section{Table 6}

Normalized Fuzzy decision matrix for example 2

\begin{tabular}{llllll}
\hline $\begin{array}{l}\text { ERP } \\
\text { system }\end{array}$ & BV & RMS & C & UI & SSS \\
\hline ORACLE & $(0.293,0.369,0.419)$ & $(0.321,0.390,0.459)$ & $(0.249,0.349,0.449)$ & $(0.284,0.345,0.406)$ & $(0.311,0.377,0.444)$ \\
SAP & $(0.293,0.377,0.419)$ & $(0.229,0.390,0.459)$ & $(0.249,0.374,0.449)$ & $(0.284,0.345,0.406)$ & $(0.311,0.399,0.444)$ \\
Axapta & $(0.042,0.231,0.377)$ & $(0.092,0.184,0.275)$ & $(0.050,0.224,0.399)$ & $(0.162,0.284,0.406)$ & $(0.089,0.178,0.266)$ \\
\hline
\end{tabular}

\section{Table 7}

Weighted Fuzzy decision matrix for example 2

\begin{tabular}{llllll}
\hline $\begin{array}{l}\text { ERP } \\
\text { system }\end{array}$ & BV & RMS & C & UI & SSS \\
\hline ORACLE & $(0.053,0.067,0.076)$ & $(0.069,0.083,0.098)$ & $(0.052,0.072,0.093)$ & $(0.052,0.063,0.075)$ & $(0.066,0.080,0.094)$ \\
SAP & $(0.053,0.069,0.076)$ & $(0.049,0.083,0.098)$ & $(0.052,0.078,0.093)$ & $(0.052,0.063,0.075)$ & $(0.066,0.084,0.094)$ \\
Axapta & $(0.008,0.042,0.069)$ & $(0.019,0.039,0.059)$ & $(0.010,0.046,0.083)$ & $(0.030,0.052,0.075)$ & $(0.019,0.038,0.056)$ \\
\hline
\end{tabular}


Table 8

Ranking of ERP systems for example 2

\begin{tabular}{llllll}
\hline ERP system & \multicolumn{2}{l}{$S^{+}$} & & & \\
\cline { 2 - 5 } & $l$ & $m$ & $u$ & & Rank \\
\hline ORACLE & 0.292 & 0.365 & 0.436 & 0.3680 & 2 \\
SAP & 0.272 & 0.377 & 0.436 & 0.3690 & 1 \\
Axapta & 0.086 & 0.217 & 0.342 & 0.2390 & 3 \\
\hline
\end{tabular}

It is noticed that SAP, started in 1972, is the world's largest inter-enterprise software organization and the world's fourth largest independent software supplier. The original SAP intends to provide customers with the ability to interact with a common corporate database for a comprehensive range of applications. Gradually, the applications have been assembled, and today many organizations, including IBM and Microsoft, are using SAP products to run their own businesses. SAP applications, built around their latest $\mathrm{R} / 3$ system, provide the capability to manage financial, asset and cost accounting, production operations and materials, personnel, plants, and archived documents. Hence, emergence of SAP as the best ERP system for both the cases can be justified to be quite obvious.

\section{Conclusions}

In the present day global competitive environment, the manufacturing organizations need to implement suitable ERP systems for their survival and achieve competitive advantage over their rivals. Evaluation and selection of an ERP system for a specific managerial function is often observed to be a cost-intensive and time-consuming task. On the other hand, the success of the manufacturing organization entirely depends on taking the full advantage of the installed ERP system. Sometimes, the information related to the performance of available ERP systems with respect to various deciding factors are vague and imprecise, and can be suitably expressed in triangular fuzzy numbers. The choice of a suitable ERP system from a pool of feasible alternatives is usually supplemented by fuzzy MCDM approaches. In this paper, fuzzy multi-objective optimization on the basis of ratio analysis method is adopted to select the best ERP systems for two organizations and it is observed that in both the cases, SAP is the best choice. As the proposed approach is simple, easy to understand and accurate, it can also be successfully applied to other managerial and strategic decision-making situations.

\section{References}

Asgari, M., Allahverdiloo, M., \& Samkhani, S. (2011). A comprehensive framework for selecting the ERP system in Iran Khodro company. European Journal of Economics, Finance and Administrative Sciences, 38, 7-19.

Ayağ, Z., \& Özdemir, G. (2007). An intelligent approach to ERP software selection through fuzzy ANP. International Journal of Production Research, 45(10), 2169-2194.

Bernroider, E.W.N., \& Mitlöhner, J. (2005). Characteristics of the multiple attribute decision making methodology in enterprise resource planning software decisions. Communications of the IIMA, 5(1), 49-58.

Brauers, W.K.M., \& Zavadskas, E.K. (2006). The MOORA method and its application to privatization in transition economy. Control and Cybernetics, 35(2), 443-468.

Brauers, W.K.M., Zavadskas, E.K., Peldschus, F., \& Turskis, Z. (2008), Multi-objective decisionmaking for road design. Transport, 23(3), 183-193.

Brauers, W.K.M., Zavadskas, E.K., Turskis, Z., \& Vilutiene, T. (2008). Multi-objective contractor's ranking by applying the MOORA method. Journal of Business Economics and Management, 9(4), 245-255.

Brauers, W.K.M., \& Ginevicius, R. (2009). Robustness in regional development studies: The case of Lithuania. Journal of Business Economics and Management, 10(2), 121-140. 
Brauers, W.K.M., \& Zavadskas, E.K. (2010). Project management by MULTIMOORA as an instrument for transition economies. Technological and Economic Development of Economy, 16(1), 5-24.

Brauers, W.K.M., \& Zavadskas, E.K. (2012). Robustness of MULTIMOORA: A method for multiobjective optimization. Informatica, 23(1), 1-25.

Cebeci, U. (2009). Fuzzy AHP-based decision support system for selecting ERP systems in textile industry by using balanced scorecard. Expert Systems with Applications, 36(5), 8900-8909.

Chakraborty, S. (2010). Application of the MOORA method for decision making in manufacturing environment. International Journal of Advanced Manufacturing Technology, 54(9-12), 11551166.

Forslund, H., \& Jonsson, P. (2010). Selection, implementation and use of ERP systems for supply chain performance management. Industrial Management \& Data Systems, 110(8), 1159-1175.

Huiqun, H., \& Guang, S. (2012). ERP software selection using the rough set and TOPSIS methods under fuzzy environment. Advances in Information Sciences and Service Sciences, 4(3), 111-118.

Karaarslan, N., \& Gundogar, E. (2009). An application for modular capability-based ERP software selection using AHP method. International Journal of Advanced Manufacturing Technology, 42(9-10), 1025-1033.

Karsak, E.E., \& Özogul, C.O. (2009). An integrated decision making approach for ERP system selection. Expert Systems with Applications, 36(1), 660-667.

Khaled, A., \& Idrissi, M.A.J. (2011). A learning driven model for ERP software selection based on the Choquet integral: small and medium enterprises context. In Ariwa, E. and El-Qawasmeh, E. (Eds.): 358-371, Springer-Verlag, Berlin.

Kracka, M., Brauers, W.K.M., \& Zavadskas, E.K. (2010). Ranking heating losses in a building by applying the MULTIMOORA. Engineering Economics, 21(4), 352-359.

Liang, S-K., \& Lien, C-T. (2007). Selecting the optimal ERP software by combining the ISO 9126 standard and fuzzy AHP approach. Contemporary Management Research, 3(1), 23-44.

Liao, X., Li, Y., \& Lu, B. (2007). A model for selecting an ERP system based on linguistic information processing. Information Systems, 32(7), 1005-1017.

Lien, C-T., \& Liang, S-K. (2005). An ERP system selection model with project management viewpoint - A fuzzy multi-criteria decision-making approach. International Journal of the Information Systems for Logistics and Management, 1(1), 39-46.

Lien, C-T., \& Chan, H-L. (2007). A selection model for ERP system by applying fuzzy AHP approach. International Journal of The Computer, the Internet and Management, 15(3), 58-72.

Nazemi, E., Tarokh, M.J., \& Djavanshir, G.R. (2012). ERP: A literature survey. International Journal of Advanced Manufacturing Technology, DOI 10.1007/s00170-011-3756-X.

Nikjoo, M.A., Khah, M.M., \& Moghimi, A. (2011). Fuzzy TOPSIS and GP application for evaluation and selection of a suitable ERP. Australian Journal of Basic and Applied Sciences, 5(11), 13581367.

Onut, S., \& Efendigil, T. (2010). A theorical model design for ERP software selection process under the constraints of cost and quality: A fuzzy approach. Journal of Intelligent \& Fuzzy Systems, 21(6), 365-378.

Rouyendegh, B.D., \& Erkan, T.E. (2011). ERP system selection by AHP method: Case study form Turkey. International Journal of Business and Management Studies, 3(1), 39-48.

Shyur, H-J. (2003). A semi-structured process for ERP systems evaluation: Applying analytic network process. Journal of e-Business, 5(1), 33-49.

Stanujkic, D., Magdalinovic, N., Stojanovic, S., \& Jovanovic, R. (2012). Extension of ratio system part of MOORA method for solving decision-making problems with interval data. Informatica, 23(1), 141-154.

Wei, C-C., \& Wang, M-J.J. (2004). A comprehensive framework for selecting an ERP system. International Journal of Project Management, 22(2), 161-169. 
Wei, C-C., Chien, C-F., \& Wang, M-J.J. (2005). An AHP-based approach to ERP system selection. International Journal of Production Economics, 96(1), 47-62.

Yazgan, H.R., Boran, S., \& Goztepe, K. (2009). An ERP software selection process with using artificial neural network based on analytic network process approach. Expert Systems with Applications, 36(5), 9214-9222.

Zadeh, L.A. (1965). Fuzzy sets. Information and Control, 8(3), 338-353. 